\title{
A NOTE ON THE RELATION BETWEEN SEARCH COSTS AND SEARCH DURATION FOR NEW HIRES
}

\author{
Francesco Carbonero \\ Universita di Torino \\ Hermann Gartner \\ Institute for Employment Research (IAB) and Friedrich-Alexander-University \\ of Erlangen-Nuremberg
}

Fixed search costs, that is, costs that do not vary with search duration, can amplify the cyclical volatility of the labor market. To assess the size of fixed costs, we analyze the relation between search costs and search duration using German establishment data. An instrumental variable estimation shows no relation between search duration and search costs. We conclude that search costs are mainly fixed costs. Furthermore, we show that a search and matching model, calibrated for Germany with fixed costs close to $75 \%$, can generate labor market volatility that is consistent with the data.

Keywords: Search Costs, Search Duration, Unemployment Volatility Puzzle

\section{INTRODUCTION}

The cyclical variation of vacancies, unemployment, and labor market tightness is empirically much larger than explained by the standard search and matching model (Shimer (2005)). A way to solve this puzzle is suggested by Pissarides (2009). He extends the standard model by distinguishing two types of search costs: those that depend on the duration of the vacancy and those that are fixed, that is, independent from the duration of the vacancy. Pissarides shows that a high share of fixed costs over the total search costs generates the elasticity of tightness with respect to productivity, as observed in the data. However, up to now, there is no empirical evidence on the plausibility of this theoretical extension.

\footnotetext{
We are grateful to Anja Bauer, Christian Merkl, Christian Offermanns, Enzo Weber, Jeffrey Wooldridge, and Josef Zweimuller for their valuable suggestions and discussion. We would also like to thank the participants of the IAB PhD Workshop 2017, the FAU-IAB Seminar on Macroeconomics and Labor Markets, and the Annual Congress of the German Economic Association 2017 for useful comments. We are grateful to the IAB team that conducts the Vacancy Survey for the support and the opportunity to introduce questions on search costs. The survey data used are confidential but not exclusive. Access to the data is provided by the Research Data Centre of the German Federal Employment Agency. For details, see http://fdz.iab.de/en/FDZ_Establishment_Data/IAB_Job_Vacancy_Survey. aspx. Address correspondence to: Hermann Gartner, Institute for Employment Research, Regensburger Strasse 104, 90478 Nuremberg, Germany. e-mail: hermann.gartner@iab.de.
}

(C) 2020 Cambridge University Press. This is an Open Access article, distributed under the terms of the Creative Commons Attribution licence (http://creativecommons.org/licenses/by/4.0/), which permits unrestricted re-use, distribution, and reproduction in any medium, provided the original work is properly cited. 1469-8056/20 263 
Our contribution is twofold. First, we empirically assess the link between search duration and search costs, and additionally, we provide evidence on the variation of search costs across firm and vacancy characteristics. Second, we provide a numerical illustration of a search and matching model for Germany with the observed structure of search cost to compare the volatility generated by the model with the volatility of the German labor market.

The related literature highlights the importance of fixed costs in the matching process. Fujita and Ramey (2007) discuss vacancy creation costs that are sunk costs. They argue that these costs affect the propagation of shocks to the vacancies by giving firms an incentive to smooth the creation of vacancies. Shao and Silos (2013) show that fixed costs raise the volatility of the value of a vacancy. Via this channel, fixed costs also influence the dynamic of the labor share. An extensive discussion of the Pissarides (2009) model is given by Silva and Toledo (2009, 2013). They highlight the difference between sunk and nonsunk (i.e., training) fixed costs. In most papers, the search costs are calibrated indirectly by matching other values such as the job-finding rate.

Search costs represent a wide range of expenditures, such as vacancy posting, screening, and negotiation activity with candidates, headhunters, or human resources staff. Despite the important implications for search models, there is scant research on the size and structure of search costs. Exceptions are, for example, Dolfin (2006) and Barron et al. (1997) or, for Germany, Mühlemann and Pfeifer (2016), but they all have no information on search duration and therefore do not distinguish between fixed and variable costs.

\section{THEORETICAL BACKGROUND}

Let us first clarify the argument of Pissarides (2009) to solve the unemployment volatility puzzle. The job-creation condition in the canonical model is

$$
\frac{p-w}{r+s}=\frac{c}{q(\theta)}
$$

where $p$ is the labor productivity, $w$ is the wage, $r$ is the risk-free interest rate, $s$ is the separation rate, $c$ is the standard search cost per period, and $q(\theta)$ is the vacancy filling rate. According to the matching function, the vacancy filling rate depends on labor market tightness $\theta$, the ratio between vacancy and unemployment. Note that $1 / q(\theta)$ is the search duration and $c / q(\theta)$ is the total search cost. It follows that the total search costs move one to one with the duration of a vacancy. We will empirically test this.

The elasticity of tightness with respect to $p$ can be expressed as

$$
\varepsilon_{\theta}=\frac{1}{\eta} \frac{p-\varepsilon_{w} w}{p-w}
$$

where $\varepsilon_{w}$ is the elasticity of the wage with respect to productivity shocks. $\eta$ is the elasticity of new matches with respect to unemployment. 
Under the standard calibration (see Pissarides (2009)) with flexible wages, $\eta=0.5$ in the Cobb-Douglas constant return matching function, $p=1$ and equilibrium values of $w=0.983$ and $\varepsilon_{w}=0.985, \varepsilon_{\theta}$ takes a value of 3.7 , while the observed elasticity in the USA is approximately 7.56. This is the core of the unemployment volatility puzzle. Note that in Germany, where our data come from, the puzzle also exists. The volatility of tightness relative to productivity in Germany is, in fact, twice as large as that in the USA. ${ }^{1}$

When adding fixed costs $H$, the job-creation condition changes as follows: ${ }^{2}$

$$
\frac{p-w}{r+s}=\frac{c}{q(\theta)}+H
$$

The elasticity of $\theta$ with respect to $p$ computed from (3) is

$$
\varepsilon_{\theta}=\frac{1}{\eta} \frac{p-\varepsilon_{w} w}{p-w-(r+s) H} .
$$

The higher the fixed search costs $H$, the lower is the reaction of tightness to a productivity shock $\varepsilon_{\theta}$. The intuition is as follows. A positive productivity shock leads to more vacancies created by the firms. This increases labor market tightness as well as vacancy duration. A higher duration also raises the search costs and thereby dampens the incentive to create vacancies. However, the higher the share of fixed search costs, the smaller this dampening effect is, and the higher the elasticity of $\theta$ is. Pissarides shows in a calibration exercise that if the share of $H$ in total search costs is approximately $93 \%$, we end up with an elasticity consistent with the data for the USA.

Note that the costs and the duration in the theoretical model are expected (i.e., ex ante) values. Later in the empirical model, we use realized (i.e., ex post) values. Under rational expectations, there are only unsystematic differences between ex ante and ex post values. They will be captured by the error term in our regression. Moreover, the model assumes homogeneity of firms and workers. In the data, firms and workers are heterogenous. We deal with this by using control variables and by running robustness checks for subgroups. Additionally, we apply an instrumental variable (IV) estimation using instruments that are exogenous for the firm.

\section{DATA AND DESCRIPTIVE EVIDENCE}

We use the German Job Vacancy Survey, conducted by the Institute for Employment Research (IAB). The survey is a random sample of establishments with at least one employee and stratified by 23 economic sectors and seven firm size classes (see Moczall et al. (2015)). The yearly survey started in 1989 and includes information on the number and structure of vacancies, worker flows, establishment size, and other firm characteristics. The number of establishments participating ranges from 4000 in the first years to about 14,000 in the recent years. The data set includes weights to extrapolate the data for the whole economy. 
It also contains a number of questions concerning the very last case of a successfully recruited worker, such as gender and age of the hired worker, the qualification required for the job, the duration of search, the number of applicants, and the recruiting channels used by the employer.

In the 2014 and 2015 waves, we included two further questions referring to the last case of recruiting: "What is the total number of hours spent on this recruitment?" and "If you add up all other costs, including advertising, headhunters, travel expenses, etc., which further costs (without labor costs) emerged for this recruiting?" The first question refers to what we call the search hours, and the second refers to the monetary search costs. To account for both the monetary search costs and the costs of the recruiting staff of the establishment, we multiply the hours spent on recruiting by the average hourly cost of labor at size, sector, yearly level, ${ }^{3}$ and we add it to the monetary search costs. This measure is the compounded search cost. ${ }^{4}$ We compute the vacancy duration as the time span between the date when the search started and the date when the applicant is selected. The data set for our analysis contains 9048 observations.

We provide the descriptive evidence across establishments and vacancy characteristics and search channels in Table 1. The average compounded search costs are 1576 Euros, similar to the result of Mühlemann and Pfeifer (2016). Our data also reveal a substantial heterogeneity in search costs and search duration. First, the monetary cost and the working time for searching are higher in larger establishments and if qualificatory requirements are high. Second, additional skill requirements, such as experience and leadership, are associated with longer duration and higher costs. Third, searching for workers on part-time or temporary contracts requires lower search costs. Finally, the channels used to find the workers reveal some unexpected results: ${ }^{5}$ according to the survey, employers spend more when they use a private employment agency, when they advertise the job internally, or when they use the Internet. More intuitive are the consequences of hiring a trainee or a new staff through social contacts. In these cases, the search costs are lower. It is worthwhile to note that the Federal Employment Agency (BA, Bundesagentur für Arbeit) is a relatively cheap search channel for employers, but it is also related to a long vacancy duration. Further descriptive results across sectors can be found in Table A.1 in the Online Appendix. The data reveal that those sectors affected by high compounded search costs also need a longer search time (in days) to find the right staff.

\section{THE EMPIRICAL RELATION OF SEARCH COSTS AND SEARCH DURATION}

Turning to the econometric analysis, our aim is to check whether and to what extent the compounded search costs (henceforth, simply search costs) are related to the search duration, conditional on vacancy, and establishment observables. Search costs and search duration enter the estimation model in logs because of a higher explanatory power than in a level specification. Thus, the coefficient can 
TABLE 1. Descriptive statistics according to plant and vacancy characteristics

\begin{tabular}{|c|c|c|c|c|c|c|c|c|c|}
\hline \multicolumn{2}{|c|}{ Characteristics } & \multicolumn{2}{|c|}{$\begin{array}{l}\text { Monetary search } \\
\text { costs (Euros) }\end{array}$} & \multicolumn{2}{|c|}{ Search hours } & \multicolumn{2}{|c|}{$\begin{array}{l}\text { Search duration } \\
\text { (days) }\end{array}$} & \multicolumn{2}{|c|}{$\begin{array}{l}\text { Comp. search } \\
\text { costs (Euros) }\end{array}$} \\
\hline \multirow{5}{*}{ Plant size (\# employees) } & $<20$ & 395 & $(1480)$ & 17 & (26) & 72 & (79) & 906 & $(1792)$ \\
\hline & $20-49$ & 582 & (1829) & 19 & (24) & 62 & (67) & 1192 & $(2261)$ \\
\hline & $50-199$ & 788 & $(2678)$ & 20 & $(34)$ & 66 & $(85)$ & 1478 & $(3297)$ \\
\hline & $200-499$ & 2568 & $(8162)$ & 18 & $(17)$ & 68 & $(68)$ & 3241 & $(8541)$ \\
\hline & $>500$ & 1374 & $(3524)$ & 22 & $(31)$ & 63 & $(58)$ & 2371 & $(4120)$ \\
\hline \multirow{5}{*}{ Qualification } & Unskilled, max. 1 year of training & 159 & $(514)$ & 18 & $(32)$ & 49 & $(56)$ & 685 & $(1345)$ \\
\hline & Vocational qualification & 489 & $(1354)$ & 17 & (23) & 67 & (79) & 1004 & $(1691)$ \\
\hline & Master craftsman, technician & 1384 & (3310) & 22 & $(30)$ & 76 & (87) & 2201 & $(3962)$ \\
\hline & Bachelor's degree & 2005 & $(8150)$ & 23 & (26) & 67 & (64) & 2943 & $(8238)$ \\
\hline & Master's degree or similar, $\mathrm{PhD}$ & 2806 & $(6640)$ & 28 & $(40)$ & 79 & (73) & 3997 & (7366) \\
\hline \multirow{2}{*}{ Additional skills } & Long experience & 1655 & $(4867)$ & 22 & $(31)$ & 78 & (76) & 2467 & $(5454)$ \\
\hline & Leadership skills & 3476 & (7669) & 30 & (45) & 87 & (82) & 4594 & $(8386)$ \\
\hline \multirow{2}{*}{ Type of contract } & Part-time & 306 & $(967)$ & 16 & (23) & 62 & (87) & 765 & $(1191)$ \\
\hline & Temporary contract & 472 & (1607) & 18 & $(28)$ & 61 & (67) & 1041 & $(2025)$ \\
\hline
\end{tabular}


TABLe 1. Continued

\begin{tabular}{|c|c|c|c|c|c|c|c|c|c|}
\hline \multicolumn{2}{|c|}{ Characteristics } & \multicolumn{2}{|c|}{$\begin{array}{l}\text { Monetary search } \\
\text { costs (Euros) }\end{array}$} & \multicolumn{2}{|c|}{ Search hours } & \multicolumn{2}{|c|}{$\begin{array}{l}\text { Search duration } \\
\quad \text { (days) }\end{array}$} & \multicolumn{2}{|c|}{$\begin{array}{l}\text { Comp. search } \\
\text { costs (Euros) }\end{array}$} \\
\hline \multirow{9}{*}{ Search channels } & Newspaper & 1202 & $(4124)$ & 21 & (27) & 75 & $(77)$ & 1834 & $(4334)$ \\
\hline & BA & 910 & (4110) & 22 & (29) & 74 & (78) & 1601 & (4442) \\
\hline & Own web site & 1291 & $(4508)$ & 21 & $(30)$ & 75 & $(80)$ & 2060 & $(4922)$ \\
\hline & Internet & 1318 & $(4500)$ & 24 & (31) & 82 & $(88)$ & 2156 & (4823) \\
\hline & Unsolicited application & 910 & (4813) & 19 & (26) & 72 & (89) & 1520 & $(5060)$ \\
\hline & Private job placement & 4315 & $(8217)$ & 30 & (33) & 93 & $(107)$ & 5371 & (9028) \\
\hline & Internal job advertisements & 1653 & $(6093)$ & 22 & (37) & 69 & $(65)$ & 2522 & $(6564)$ \\
\hline & Social contact & 547 & $(2363)$ & 17 & $(25)$ & 71 & $(89)$ & 1097 & $(2699)$ \\
\hline & Trainee & 825 & (2187) & 17 & (19) & 84 & (116) & 1413 & (2608) \\
\hline Overall mean & & 920 & $(3652)$ & 19 & (28) & 67 & (75) & 1576 & (4051) \\
\hline
\end{tabular}

23 economic sectors and seven firm size classes. 
be interpreted as elasticity of search costs with respect to search duration. At first, we present results from an ordinary least squares (OLS) approach to document the comovements in the data. Because of potential endogeneity, we interpret these results as correlations not as causations. Later, we use an instrumental variable approach that allows for a causal interpretation.

The results of the OLS models are presented in Table 2. We add subsets of covariates progressively from Model 1 to Model 3 to provide information on the specific contribution of the characteristics. The results confirm the descriptive evidence, with more consistent results for the search channels-the inclusion of additional variables improves strongly the explained variation of the dependent variable. The coefficient of search duration is positive and significant in all specifications. Model 1, regressing only on firm size and sectors, shows an elasticity of search costs to search duration of $37 \%$. In Model 2, we also account for qualification, further skill requirements, and type of contract, and the elasticity shrinks to $32 \%$. Looking at Model 3, where we account for all controls, the elasticity is much smaller: a $10 \%$ increase in search duration is associated with an increase in the search costs of $2 \%$. The result reveals a positive relation of search costs and duration, but the elasticity is much smaller than one, as asserted by the canonical search and matching model.

In regard to the control variables, the table shows that large firms face higher search costs and that required qualification and additional skills are positively correlated with search costs, while hiring a worker for a temporary or a part-time contract is correlated with lower search costs.

Concerning the search channels, when firms search via social contacts or among the trainees, they save on some search costs. The coefficient of the BA is the smallest among the channels with a positive correlation. Using a newspaper or private job placement is associated with the highest search costs. Finally, hiring an underexperienced worker correlates positively with the search costs; a possible reason for this is that employers with high search costs accept underexperienced staff to finish the search sooner (this is a finding of Brenčič and Norris (2009)). This is a causal question that we leave for future research.

The OLS estimates can be criticized because there may be unobserved firm characteristics that influence search duration as well as search costs. Therefore, we adopt an instrumental variable approach. As instruments we use variables that are exogenous for the firm and that are motivated by the standard search and matching model. According to the model, the expected duration of the vacancy is a function, $1 / q(\theta)$, of labor market tightness. Therefore, we use the log of labor market tightness at district (Kreise) level to instrument the search duration. ${ }^{6}$ The first-stage regression model is basically a matching function. We estimate fixed effects for 400 districts, and thus, the result is driven by the time variation within the districts. The same control variables as in Model 3 are included.

Table 3 displays the first- and second-stage estimation. In the first stage, labor market tightness is significant and reveals an impact on search duration consistent with the matching model: a higher number of vacancies make the hiring process 
TABLE 2. Continued

\begin{tabular}{|c|c|c|c|c|c|}
\hline \multicolumn{2}{|c|}{ Dependent variable: log of compounded search costs } & \multirow[t]{2}{*}{ Model 1} & \multirow[t]{2}{*}{ Model 2} & \multicolumn{2}{|c|}{ Model 3} \\
\hline \multirow{9}{*}{ Search channels } & Newspaper & & & $0.79^{* * *}$ & $(0.03)$ \\
\hline & $\mathrm{BA}$ & & & $0.16^{* * *}$ & $(0.03)$ \\
\hline & Own website & & & $0.27^{* * *}$ & $(0.03)$ \\
\hline & Internet & & & $0.41^{* * *}$ & $(0.03)$ \\
\hline & Unsolicited application & & & -0.01 & $(0.03)$ \\
\hline & Private job placement & & & $0.76^{* * *}$ & $(0.06)$ \\
\hline & Internal job advertisements & & & $0.31^{* * *}$ & $(0.03)$ \\
\hline & Social contact & & & $-0.20^{* * *}$ & $(0.03)$ \\
\hline & Trainee & & & $-0.13^{*}$ & $(0.06)$ \\
\hline \multirow{4}{*}{ Mismatch } & Underqualification & & & -0.05 & $(0.06)$ \\
\hline & Underexperience & & & $0.16^{* *}$ & $(0.05)$ \\
\hline & Sectors & Yes & Yes & \multicolumn{2}{|c|}{ Yes } \\
\hline & $R^{2}$ & 0.18 & 0.24 & \multicolumn{2}{|c|}{0.39} \\
\hline
\end{tabular}

Notes: Robust standard errors in parentheses. 9048 observations. Reference group: Plant size $20-49$, Vocational qualification. Significance levels: ${ }^{*},{ }^{* *},{ }^{* * *}$ indicate significance at $0.05,0.01$, and 0.001. Industry coefficients are in Table A.2 in the Online Appendix. 
TABLE 3. IV Regression: Search cost and search duration

\begin{tabular}{lcc}
\hline Dependent variable & $\begin{array}{c}\text { First-stage FE } \\
\text { Log of search duration }\end{array}$ & $\begin{array}{c}\text { Second-stage FE } \\
\text { Log of compounded search costs }\end{array}$ \\
\hline Log of regional tightness & $\begin{array}{c}0.55^{* * *} \\
(0.00)\end{array}$ \\
Log of search duration & & -0.35 \\
& & $(0.15)$ \\
\hline$R^{2}$ & 0.10 & 0.26 \\
\hline
\end{tabular}

Notes: Regressions with fixed effects (FEs) for the region. Robust standard errors in parentheses. 9048 observations, F-statistics in the first stage 27.42. Significance levels: ${ }^{*},{ }^{* *},{ }^{* * *}$ indicate significance at $0.05,0.01$, and 0.001 . Controls: plant size, qualification, required additional skills, type of contract, search channels, and sectors.

more competitive for the firms and increase search duration, while a higher number of unemployed make the hiring process quicker and reduce search duration. Note that the coefficient 0.55 is the elasticity in the matching function (because if $q=u^{\eta} v^{1-\eta}$, then $\left.1 / q=\theta^{\eta}\right)$. The value is in the range of $0.5-0.7$ that is according to Petrongolo and Pissarides (2001) the range of plausible values.

In the second stage, the significance of the logarithm of search duration vanishes, implying that longer search duration does not imply higher search costs. In other words, these results suggest that search costs are mainly fixed. To summarize, according to the OLS estimate, search costs move very little with search duration. The instrumental variable estimate confirms and strengthens this search cost structure. In the next section, we calibrate a search and matching model for the German labor market, and we assess the role of the structure of search cost for the unemployment volatility puzzle.

We run several additional regressions as robustness checks. We estimate separate regressions for three qualification levels of the new hires and separate regressions for manufacturing and service sectors. Furthermore, we estimate a model with a fixed effect on a three-digit occupation level. The results of these regressions are stable for the OLS and IV regressions. The results are also robust when we use as instrument unemployment and vacancies, separately, instead of tightness. The robustness checks can be found in the Online Appendix.

\section{THE ROLE OF SEARCH COSTS}

As discussed in Section 2, Pissarides (2009) shows that the existence of fixed search costs increases the response of tightness to a labor productivity shock. In the absence of data on the search cost structure, he proposes a tentative calibration of how the elasticity of tightness, $\varepsilon_{\theta}$, changes with different shares of fixed over total search costs. To relate our empirical finding on search costs in Germany to the unemployment volatility puzzle, we have to calculate the impact of fixed search costs in a model calibrated for the German labor market. 
TABLE 4. Parameter values

\begin{tabular}{|c|c|c|c|}
\hline Parameter & Value & Description & Source/Target \\
\hline$r$ & 0.004 & Interest rate & Pissarides (2009) \\
\hline$s$ & 0.013 & Exogenous separation rate & Gartner et al. (2009) \\
\hline$z$ & 0.86 & $\begin{array}{l}\text { Unemployment benefits (UB) and } \\
\text { value of leisure time }\end{array}$ & Tightness \\
\hline$m_{0}$ & 0.2 & Matching efficiency & Job-finding probability \\
\hline$\eta$ & 0.75 & Unemployment elasticity & Kohlbrecher et al. (2016) \\
\hline$\beta$ & 0.75 & $\begin{array}{l}\text { Share of labor } \\
\text { Mean values }\end{array}$ & $\beta=\eta$ (efficiency) \\
\hline$\theta$ & 0.39 & Mean tightness & Gartner et al. (2009) \\
\hline$m_{0} \theta^{1-\eta}$ & 0.13 & Job-finding probability & Gartner et al. (2009) \\
\hline
\end{tabular}

Following Pissarides (2009), we assume a Cobb-Douglas matching function $m=m_{0} u^{\eta} v^{1-\eta}$, and we use the job-creation condition (equation (3)) and the wage equation

$$
w=(1-\beta) z+\beta(p+c \theta+f(\theta) H),
$$

to solve the model for the two endogenous variables $\theta$ and $w$.

The output per worker is normalized to one. To calibrate the model with monthly data, we adopt the key structural parameters from long-run values established in the literature (see Table 4). We obtain the job-finding probability, separation rate, and labor market tightness for Germany from Gartner et al. (2009). Using the same data source, Kohlbrecher et al. (2016) estimated a matching elasticity of 0.75 which we take for $\eta$.

In most other applications, the search costs are chosen to match the tightness or the job-finding rate. As we have information on the search costs, we go another way: the total search cost presented in Section 2 is 1576 Euro. The average monthly value added per worker in 2014 and 2015 is 5155.72 Euro. $^{7}$ Thus, the search cost as a share of workers' monthly output is $31 \%$. We compute the model for several combinations of $c$ and $H$, keeping the total search costs constant at 0.31 . Finally, the nonlabor income $z$ is then chosen to match the tightness $\theta$.

Table 5 displays the results. The first line assumes no fixed search costs, as in the canonical search model. It turns out that the elasticity of tightness with respect to labor productivity $\varepsilon_{\theta}$ equals 7.16 . To compare it with the data, we compute the elasticity using the summary statistics from Gartner et al. (2009). The elasticity in the data is much larger and amounts to 17.09. This gap reflects the existence of the unemployment volatility puzzle in Germany as well.

In the subsequent lines, we show the implications of an increasing share of the fixed component $H$ for the elasticity of the labor market tightness. As we have shown in the empirical section, the data suggest that the share of fixed costs is large. When the fixed costs reach about three-quarters of the overall search 
TABLE 5. Model results at different combinations of search costs

\begin{tabular}{lclcc}
\hline$H$ & $c$ & $H_{s}$ & $\frac{c}{q(\theta)}+H$ & $\varepsilon_{\theta}$ \\
\hline 0 & 0.104 & 0 & 0.31 & 7.16 \\
0.02 & 0.097 & 0.07 & 0.31 & 7.58 \\
0.08 & 0.078 & 0.25 & 0.31 & 8.93 \\
0.14 & 0.056 & 0.46 & 0.31 & 11.24 \\
0.23 & 0.027 & 0.74 & 0.31 & 17.06 \\
\hline
\end{tabular}

costs, precisely $74 \%$, the model generates the amplification of the labor market tightness that we see in the data. This result gives support, at least for Germany, to the solution of the Shimer puzzle proposed by Pissarides (2009).

We have applied a basic search and matching model to relate the results to Pissarides (2009). One might argue that the assumption of an exogenous separation rate is plausible for the USA but not for Germany, where the volatility of the separation rate is higher (see Gartner et al. (2012)). The separation rate could also be modeled as an endogenous variable. This would establish an additional channel for amplifying the volatility. A discussion of this can be found in Fujita and Ramey (2012).

Furthermore, a difference to the US labor market is that the flow rates in Germany are smaller. This could lead to a bias when the observed values are compared with the steady state in the model. However, this bias is small: as Carrillo-Tudela et al. (2018) demonstrate for Germany, the stationary distribution of unemployment that is computed from the flows gives a good approximation of the observed values.

\section{CONCLUSION}

In this paper, we estimate the magnitude of search costs and analyze the relation of search costs with search duration. Using new information from the German Job Vacancy Survey, we measure the cost of advertising the job, paying headhunters, and inviting and screening candidates as well as the cost of the staff within the establishment that deals with the hiring process. According to an OLS analysis, the elasticity between search costs and search duration is 0.20 . This is much smaller than one, as assumed in the canonical search and matching model. If an IV regression is applied, with labor market tightness at the district level as the instrument, we find no significant relation between search duration and search costs. This suggests that search costs are mainly fixed costs, as proposed by Pissarides (2009).

We calibrate the Pissarides (2009) model for Germany. The model can generate the elasticity of labor market tightness with respect to productivity of 17.09 when the search costs are composed in large part by fixed costs, as is consistent with our empirical finding. 
The German Job Vacancy Survey allows for a deeper analysis of the heterogeneity of search costs and can thus help foster a better understanding of matching in the labor market. Future research should analyze in greater detail the relation of search costs with different matching technologies related with different search channels. The relation of search costs with recruiting intensity (Davis et al. (2013)) is also an issue for future work.

\section{SUPPLEMENTARY MATERIAL}

To view supplementary material for this article, please visit http://doi.org/10. 1017/S136510052000005X.

\section{NOTES}

1. For a detailed discussion about the volatility of the German labor market, see Gartner et al. (2012) and Rahn and Weber (2019).

2. According to Pissarides, fixed search costs $H$ enter the model without modifying the Nashbargaining equation because this is a cost not taken into account at the moment of the bargain, but it enters the value of a new vacancy.

3. The data come from the German Federal Statistical Office.

4. Note that we have no information on multiple hirings at the same time. Thus, we cannot exclude a possible bias because of scale effects. We believe, however, this bias is limited: most establishments are small and have only a few hirings per year. $54 \%$ of the establishments that report hirings had only one within a year, and $67 \%$ had not more than two hirings. Thus, parallel hirings should be rare. Furthermore, a qualitative pretest showed that, even in the case of a multiple hiring, it was mostly for different positions and the interviewee was able to separate the costs.

5. Note that a firm can use more than one search channel at the same time.

6. Labor market tightness is defined as vacancies over unemployed.

7. Source: German Federal Statistical Office. The values for 2015 are deflated to 2014 price levels.

\section{REFERENCES}

Barron, J. M., M. C. Berger and D. A. Black (1997) Employer search, training, and vacancy duration. Economic Inquiry 35(1), 167-192.

Brenčič, V. and J. B. Norris (2009) Employers' online search: An empirical analysis. Industrial Relations: A Journal of Economy and Society 48(4), 684-709.

Carrillo-Tudela, C., A. Launov, and J.-M. Robin (2018) The Fall in German Unemployment: A Flow Analysis. IZA Discussion Papers 11442, Institute of Labor Economics (IZA).

Davis, S. R., J. Faberman and J. C. Haltiwanger (2013) The establishment-level behavior of vacancies and hiring. The Quarterly Journal of Economics 128(2), 581-622.

Dolfin, S. (2006) An examination of firms' employment costs. Applied Economics 38(8), 861-878.

Fujita, S. and G. Ramey (2007) Job matching and propagation. Journal of Economic Dynamics and Control 31(11), 3671-3698.

Fujita, S. and G. Ramey (2012) Exogenous versus endogenous separation. American Economic Journal: Macroeconomics 4(4), 68-93.

Gartner, H., C. Merkl and T. Rothe (2009) They Are Even Larger! More (on) Puzzling Labor Market Volatilities. IZA Discussion Paper No. 4403.

Gartner, H., C. Merkl and T. Rothe (2012) Sclerosis and large volatilities: Two sides of the same coin. Economics Letters 117(1), 106-109. 
Kohlbrecher, B., C. Merkl and D. Nordmeier (2016) Revisiting the matching function. Journal of Economic Dynamics and Control 69, 350-374.

Moczall, A., A. Müller, M. Rebien, and K. Vogler-Ludwig (2015) The IAB Job Vacancy Survey. Establishment Survey On Job Vacancies and Recruitment Processes. FDZ-Datenreport 04/2015, FDZ, Nürnberg.

Mühlemann, S. and H. Pfeifer (2016) The structure of hiring costs in Germany: Evidence from firmlevel data. Industrial Relations: A Journal of Economy and Society 55(2), 193-218.

Petrongolo, B. and C. A. Pissarides (2001) Looking into the black box: A survey of the matching function. Journal of Economic Literature 39(2), 390-431.

Pissarides, C. (2009) The unemployment volatility puzzle: Is wage stickiness the answer? Econometrica 77(5), 1339-1369.

Rahn, D. and E. Weber (2019) Patterns of unemployment dynamics in Germany. Macroeconomic Dynamics 23(1), 322-357.

Shao, E. and P. Silos (2013) Entry costs and labor market dynamics. European Economic Review 63(C), 243-255.

Shimer, R. (2005) The cyclical behavior of equilibrium unemployment and vacancies. American Economic Review 95(1), 25-49.

Silva, J. I. and M. Toledo (2009) Labor turnover costs and the cyclical behavior Of vacancies and unemployment. Macroeconomic Dynamics 13(S1), 76-96.

Silva, J. I. and M. Toledo (2013) The unemployment volatility puzzle: The role Of matching costs revisited. Economic Inquiry 51(1), 836-843. 